\title{
COMPARISON OF THE FLIGHT LOADS SPECTRA OF TWO BUSINESS JETS
}

\author{
Linda K. Kliment \\ Kamran Rokhsaz \\ Department of Aerospace Engineering \\ Wichita State University, Wichita, KS 67260-0044 \\ United States of America \\ Linda.Kliment@Wichita.edu, Kamran.Rokhsaz@Wichita.edu
}

\begin{abstract}
Operational flight loads have been analyzed from two business jets, a Global 5000 and a Global Express XRS. It is shown that both airframes were subjected to nearly the same number of ground-air-ground cycles, even though the flight times were much different. Flights have been divided into various phases, and loads and turbulence data have been categorized by altitude bands within each phase. Cumulative occurrences of incremental vertical gust load factors have been compared and shown to be comparable for the two airframes. Maneuver load factors have been shown to spread over a wider range of values for the 5000 in every phase. This has been confirmed through comparison of combined loads with those from a CRJ100 and an ERJ-145XR. Derived gust velocities, obtained from the load factors are presented in the form of exceedance spectra. These results from both aircraft are shown to agree well
\end{abstract}

Keywords: load spectrum, derived gust velocity, business jet operations

\section{NOMENCLATURE}

$a_{w b}=$ lift-curve slope of the wing-body combination $\approx a_{w}, 1 / \mathrm{rad}$

$a_{t}=$ lift-curve slope of the horizontal tail, $1 / \mathrm{rad}$

$A_{r}=\quad$ aspect ratio of wing or horizontal tail

$b \quad=\quad$ wing span, $\mathrm{ft}$

$\bar{c}=$ wing mean geometric chord, $\mathrm{ft}$

$\bar{C}=$ aircraft response factor

$C_{L_{\alpha}}=$ aircraft lift-curve slope, $1 / \mathrm{rad}$

$C_{L_{\alpha}}=$ aircraft lift-curve slope, $1 / \mathrm{rad}$

$g=32.2 \mathrm{ft} / \mathrm{s}^{2}$, acceleration of gravity

$h_{H} \quad=\quad$ height of the tail above the wing, $\mathrm{ft}$

$K_{g}=\frac{0.88 \mu_{g}}{5.3+\mu_{g}}$, gust alleviation factor

$l_{H} \quad=\quad$ longitudinal distance from wing mean aerodynamic quarter chord to tail, $\mathrm{ft}$

$P \quad=\quad$ pressure, $\mathrm{psf}$ 


$\begin{array}{lll}R & = & 1,716 \mathrm{ft}-\mathrm{lb} / \text { slug- } \mathrm{R}, \text { specific gas constant } \\ S & = & \text { wing reference area, } \mathrm{ft}^{2} \\ S_{t} & = & \text { horizontal tail area, } \mathrm{ft}^{2} \\ T & = & \text { temperature, } \mathrm{R} \\ U_{d e} & = & \text { derived gust velocity, } \mathrm{ft} / \mathrm{s} \\ V_{i} & = & \text { indicated airspeed, } \mathrm{ft} / \mathrm{s} \\ V_{\mathrm{e}} & = & \text { equivalent airspeed, } \mathrm{ft} / \mathrm{s} \\ V_{t} & = & \text { true airspeed, } \mathrm{ft} / \mathrm{s} \\ W & = & \text { typical operating weight, } \mathrm{lb}\end{array}$

Greek Symbols

$\begin{array}{lll}\beta & = & \text { compressibility factor, } \sqrt{1-M^{2}} \\ \gamma & = & \text { ratio of specific heat constants } \\ \Delta n_{z} & = & \text { incremental peak gust vertical load factor, } \mathrm{g} \\ \frac{\partial \varepsilon}{\partial \alpha} & = & \text { downwash gradient at the horizontal tail } \\ \kappa & = & \text { airfoil lift-curve slope divided by }(2 \pi) \\ \lambda & = & \text { wing taper ratio } \\ \Lambda_{0.25 c} & = & \text { sweep of the wing at quarter chord } \\ \Lambda_{0.5 c} & = & \text { sweep of the wing or horizontal tail at half chord } \\ \mu_{g} & = & \frac{2 W}{\rho g \bar{c} C_{L_{\alpha}} S}, \text { reduced mass } \\ \rho & = & \text { air density at altitude, slug/ } \mathrm{ft}^{3} \\ \rho_{0} & = & 0.002377 \text { slug/ } \mathrm{ft}^{3}, \text { standard sea level air density }\end{array}$

\section{INTRODUCTION}

ON April 28, 1988, Aloha flight 243, en route from Hilo to Honolulu, experienced an explosive decompression at $24,000 \mathrm{ft}$ due to in-flight structural failure resulting in the separation of approximately 18 feet of the upper skin behind the cockpit (Figure 1). The aircraft, a Boeing 737200, was landed successfully at Kahului airport on the island of Maui, although the accident resulted in one death and several severe injuries. Subsequently, the National Transportation Safety Board (NTSB) determined ${ }^{1}$ the cause of the accident to be the failure of the airline's maintenance program to detect the presence of fatigue damage on the upper fuselage.

This accident attracted a great deal of public attention, coining the phrase "aging aircraft". Subsequently, the Federal Aviation Administration (FAA) developed programs in Operational Loads Monitoring (OLM) to better understand issues affecting aircraft fatigue life stemming from in-flight loads experienced by the airframe and the type of usage compared to the design standards. Since then, data has been collected and analyzed on a wide variety of aircraft, some of which can be found in References [2] through [8]. This type of data is crucial for the development of loads exceedance spectra used for fail safe and safe life evaluations. Creating the processed data in statistical formats can enable the FAA, the manufacturer, and the operator to better understand and control those factors that influence the structural integrity of these aircraft. The first group can use this information to examine the relevance of the existing regulation. The second group can benefit from this data by using it to refine its design standards, while the operators can adjust their maintenance procedures to better fit their specific operations. 
There is considerable flight loads information available on aircraft certified under FAR25 flying in various airline operations. However, little comparable information is available on aircraft operating as business jets under either FAR23 or FAR25. Some of the data from airline operations can be applied to establish operational and design standards for business jets. However, the large variations in type and nature of operations call for a detailed analysis of aircraft flown in this role.

In the present article, the authors show exceedance spectra derived from actual operations of two similar airframes flown in varying missions. Actual recorded flight data is used to arrive at statistical information concerning the airframe loads and atmospheric turbulence. Where applicable, this information is also compared with those used for design. The comparison of the data coming from the two airframes highlights the differences in their missions and their usage, which may necessitate different maintenance schedules.

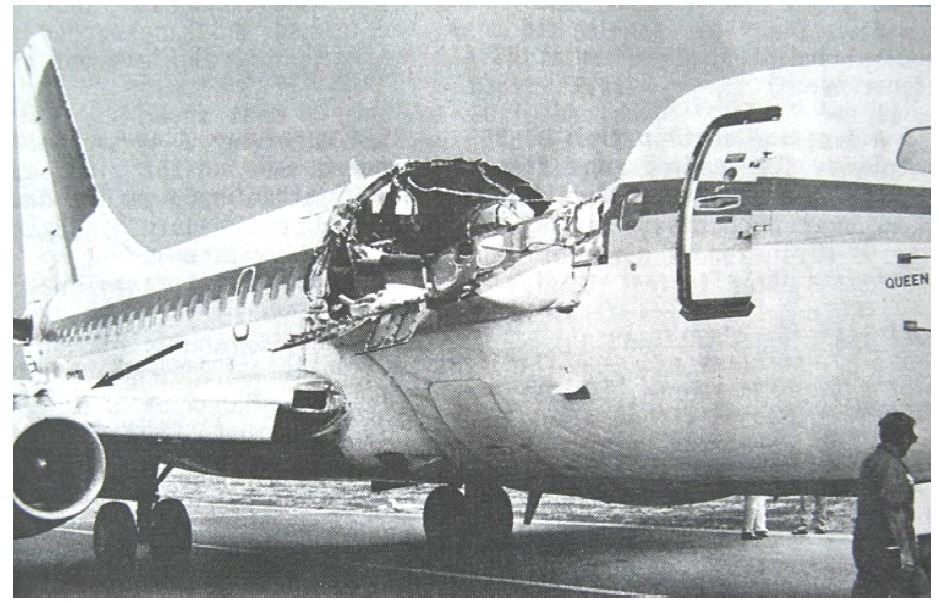

Figure 1. Aloha flight 243 after in-flight structural failure [1]

\section{AIRCRAFT AND DATA DESCRIPTION}

\section{Aircraft Description}

The two airframes used for this study consisted of a Bombardier Global Express XRS and a Global 5000. From this point on, the two aircraft will be referred to as "the XRS" and "the 5000 ", respectively. The XRS is a slightly stretched version of the 5000 for extended range. The XRS was used as a standard business jet with simple ground-air-ground (GAG) cycles, similar to an airliner, while the 5000, was used in support of FAA and was flown for various missions including verification of airspace procedures. In this role, the aircraft was sometimes used for multiple and successive touch-and-goes and other relatively low-altitude flights. Both aircraft were certified for flight up to 51,000 ft and could reach Mach 0.89 in cruise. Some features of the two designs are shown in Table 1.

\section{Recorded Flight Data}

Quick Access Recorders (QARs) were installed on both aircraft. The QAR is an independent recording system that records the same data as the Flight Data Recorder (FDR). A QAR device at 128 channels can record 1500 hours of flight data as compared to 25 hours of flight data on an FDR device; thus reducing the frequency of downloads [10]. The XRS was equipped with a 128channel recorder, while 256 channels were recorded on the 5000. Not all data was recorded at the same rate, as shown in Table 2. However, for ease of analysis, all parameters were interpolated to $8 \mathrm{~Hz}$. 


\section{METHOD OF ANALYSIS}

\section{A. Data Processing}

Some processing of the data was necessary in order to facilitate the analysis. Altitude recordings were somewhat noisy so they were filtered using a two-second running average. This resulted in acceptable noise for determination of rate of climb. Also, accelerometer readings were normalized relative to their initial readings before start of taxi-out.

Takeoff and landing times were based on squat switch recordings. The aircraft was equipped with three such switches. Therefore, liftoff was assumed when all three indicated being in the air. On the other hand, touchdown was marked if any indicated weight on wheel.

In the absence of local pressure and temperature recordings, standard atmosphere was assumed based on pressure altitude readings. These were used to derive true and equivalent airspeeds from the indicated airspeed. Since the aircraft was operated mostly in the compressible flow regime, Equation 1 was used to arrive at indicated airspeed.

$$
V_{t}^{2}=\frac{2(\gamma R T)}{\gamma-1}\left\{\left[\frac{1}{2} \frac{\rho_{0} V_{i}^{2}}{P}+1\right]^{\frac{\gamma-1}{\gamma}}-1\right\}
$$

Table 1. Comparison of the two aircraft [9]

\begin{tabular}{l|r|r}
\hline \multicolumn{1}{c|}{ Parameter } & Global 5000 & $\begin{array}{c}\text { Global Express } \\
\text { XRS }\end{array}$ \\
\hline \hline Crew (Passengers) & $2-3(8-17)$ & $2-4(8-19)$ \\
Range at M = 0.85 (nm) & 5,200 & 6,000 \\
Maximum Speed (Mach, KTAS) & $0.89(513)$ & $0.89(513)$ \\
Typical Cruise Speed (Mach, KTAS) & $0.85(488)$ & $0.85(488)$ \\
Maximum Operating Altitude (ft) & 51,000 & 51,000 \\
Geometry & & \\
Length (ft) & 96.8 & 99.4 \\
Wing Span (ft) & 94.0 & 94.0 \\
Height (ft) & 25.5 & 25.5 \\
Wing Area (ft ${ }^{2}$ ) & $1,022.0$ & $1,022.0$ \\
Wing Aspect Ratio & 8.6 & 8.6 \\
Wing Average Chord (ft) ${ }^{*}$ & 10.87 & 10.87 \\
Weights & & 99,500 \\
Maximum Takeoff Weight (pounds) & 92,500 & 52,230 \\
Typical Basic Operating Weight & 50,840 & \\
(pounds) & & \\
\hline
\end{tabular}

* Derived quantities 
Table 2. Some recorded parameters and their recording frequencies

\begin{tabular}{l|l|c}
\hline \multicolumn{1}{c|}{ Parameter } & Units & Sample Rate (Hz) \\
\hline \hline Time & Seconds & 8 \\
Indicated Airspeed & Knots & 0.5 \\
Pressure Altitude & Feet & 1 \\
Total Temperature & Celsius & 0.5 \\
Vertical Acceleration & $\mathrm{g}$ & 8 \\
Longitudinal Acceleration & $\mathrm{g}$ & 4 \\
Lateral Acceleration & g & 4 \\
Heading & degrees & 1 \\
Pitch & degrees & 4 \\
Roll & degrees & 2 \\
GPS Latitude & degrees & 1 \\
GPS Longitude & degrees & 1 \\
Left Angle of Attack & degrees & 1 \\
Right Angle of Attack & degrees & 1 \\
Flap & Integer & 1 \\
Slat & Integer & 1 \\
Weight on Wheel - left & Ground/Air & 4 \\
Weight on Wheel - middle & Ground/Air & 4 \\
Weight on Wheel - right & Ground/Air & 4 \\
Right Engine Fan Speed & Percentage & 1 \\
Right Engine Core Speed & Percentage & 1 \\
Left Engine Fan Speed & Percentage & 1 \\
Left Engine Core Speed & Percentage & 1 \\
& &
\end{tabular}

Equivalent airspeed was determined from

$$
V_{e}=V_{t} \sqrt{\frac{\rho}{\rho_{0}}}
$$

Method of peaks-between-means, presented in a variety of references (e.g. Reference [3]), was used to count the occurrences of various parameters. To eliminate the effects of extraneous noise, dead bands were introduced around level-flight conditions. These dead bands are shown in Table 4.

\section{B. Atmospheric Turbulence}

From the gust loads, discrete gust velocities were derived to model the atmospheric turbulence. Aircraft lift-curve slope was estimated using the methods of Reference [11].

$$
C_{L_{\alpha}}=a_{w b}\left[1+\frac{a_{t}}{a_{w b}} \frac{S_{t}}{S}\left(1-\frac{\partial \varepsilon}{\partial \alpha}\right)\right]
$$

The wing lift-curve-slope, $a_{w}$, and tail lift-curve-slope, $a_{t}$, were calculated from

$$
a_{w}, a_{t}=\frac{2 \pi A_{r}}{2+\sqrt{\frac{A_{r}^{2} \beta^{2}}{\kappa^{2}}\left(1+\frac{\tan ^{2} \Lambda_{0.5 c}}{\beta^{2}}+4\right)}}
$$




\section{Table 3. Pressure altitude bands}

\begin{tabular}{c|l}
\hline \hline Band & Altitude (ft) \\
\hline \hline 1 & $<500$ \\
2 & $500-1500$ \\
3 & $1500-4500$ \\
4 & $4500-9500$ \\
5 & $9500-14500$ \\
6 & $14500-19500$ \\
7 & $19500-24500$ \\
8 & $24500-29500$ \\
9 & $29500-34500$ \\
10 & $34500-39500$ \\
11 & $>39500$ \\
\hline
\end{tabular}

Table 4. Dead band limits

\begin{tabular}{l|c}
\hline \hline \multicolumn{1}{c|}{ Parameter } & Dead Band Width \\
\hline \hline Incremental Normal Acceleration & $\pm 0.05 \mathrm{~g}$ \\
Lateral Acceleration & $\pm 0.005 \mathrm{~g}$ \\
Longitudinal Acceleration & $\pm 0.005 \mathrm{~g}$ \\
Derived/Continuous Gust Velocity & $\pm 2.00 \mathrm{ft} / \mathrm{s}$ \\
\hline
\end{tabular}

Downwash gradient was calculated from [11]

$$
\frac{\partial \varepsilon}{\partial \alpha}=4.44\left[\left(\frac{1}{A_{r}}-\frac{1}{1+A_{r}^{1.7}}\right)\left(\frac{10-3 \lambda}{7}\right)\left(\frac{1-\left|h_{H} / b\right|}{\sqrt[3]{2 l_{H} / b}}\right) \sqrt{\cos \left(\Lambda_{0.25 c}\right)}\right]^{1.19}
$$

Lift-curve-slope for the wing-body combination was assumed to equal the lift-curve-slope for the wing.

Knowing gust-induced normal accelerations, derived gust velocity was calculated with

$$
U_{d e}=\frac{\Delta n_{z}}{\bar{C}}
$$

where the aircraft response factor, $\bar{C}$, was given by

$$
\bar{C}=\frac{\rho_{0} C_{L_{\alpha}} S V_{e}}{2 W} K_{g}
$$

Aircraft weight was not a recorded parameter. Therefore, typical basic operating weights shown in Table 1 were used.

\section{Flight Phase Separation}

Airborne parts of the flights were divided into seven segments. Ground operations consisted of six phases, including takeoff rotations. The criteria concerning phase recognition and separation are shown in Table 5. These phases are shown schematically in Figure 2, while Figure 3 from an actual operation is shown for comparison. This figure shows the time history of two flights from the 5000, separated by one touch-an-go. In these cases, each flight was analyzed separately. The 
flight loads were examined for each phase, as well as for the entire flight. The detailed information concerning individual phases for the XRS can be found in Reference [12]. The present article contains the highlights plus comparable information about the 5000. Here, the emphasis is placed on comparison of the loads experienced by the two airframes.

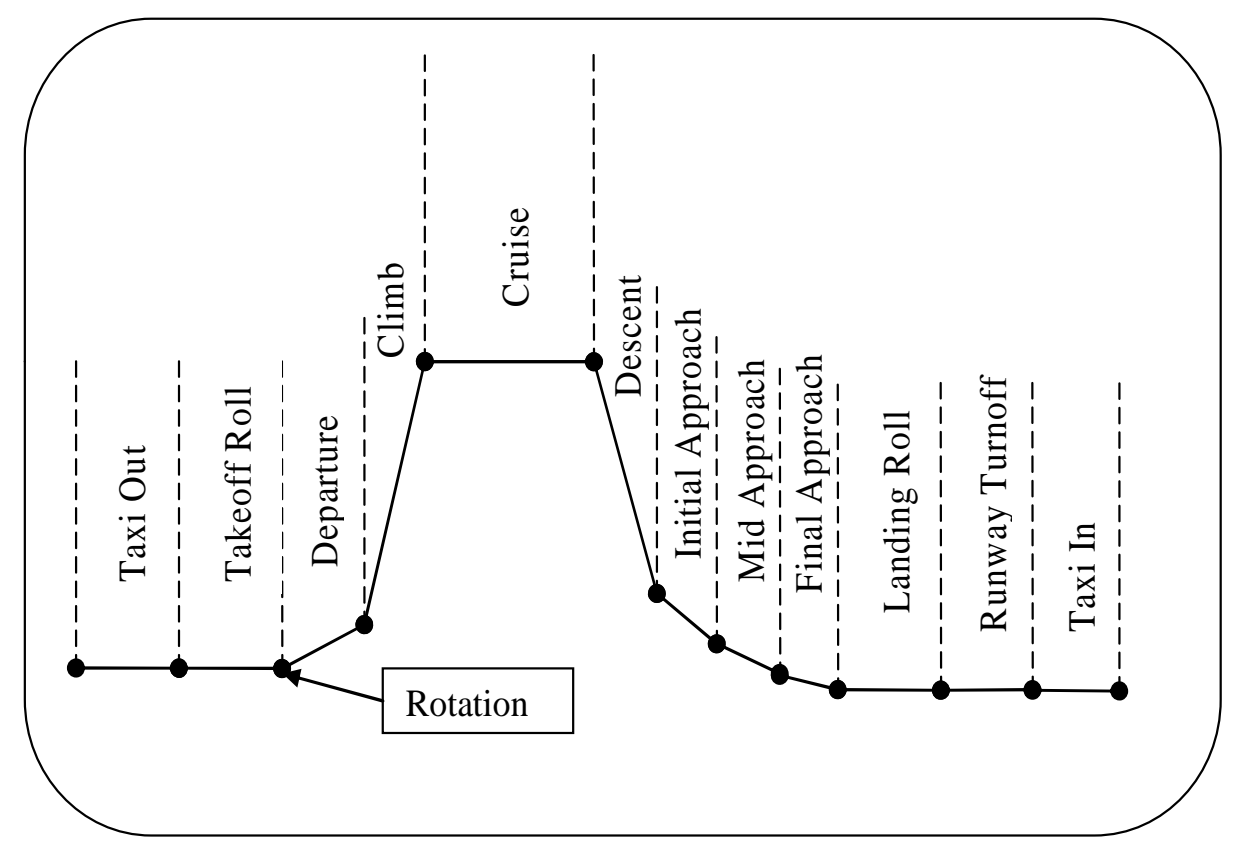

Figure 2. Schematic of various flight phases

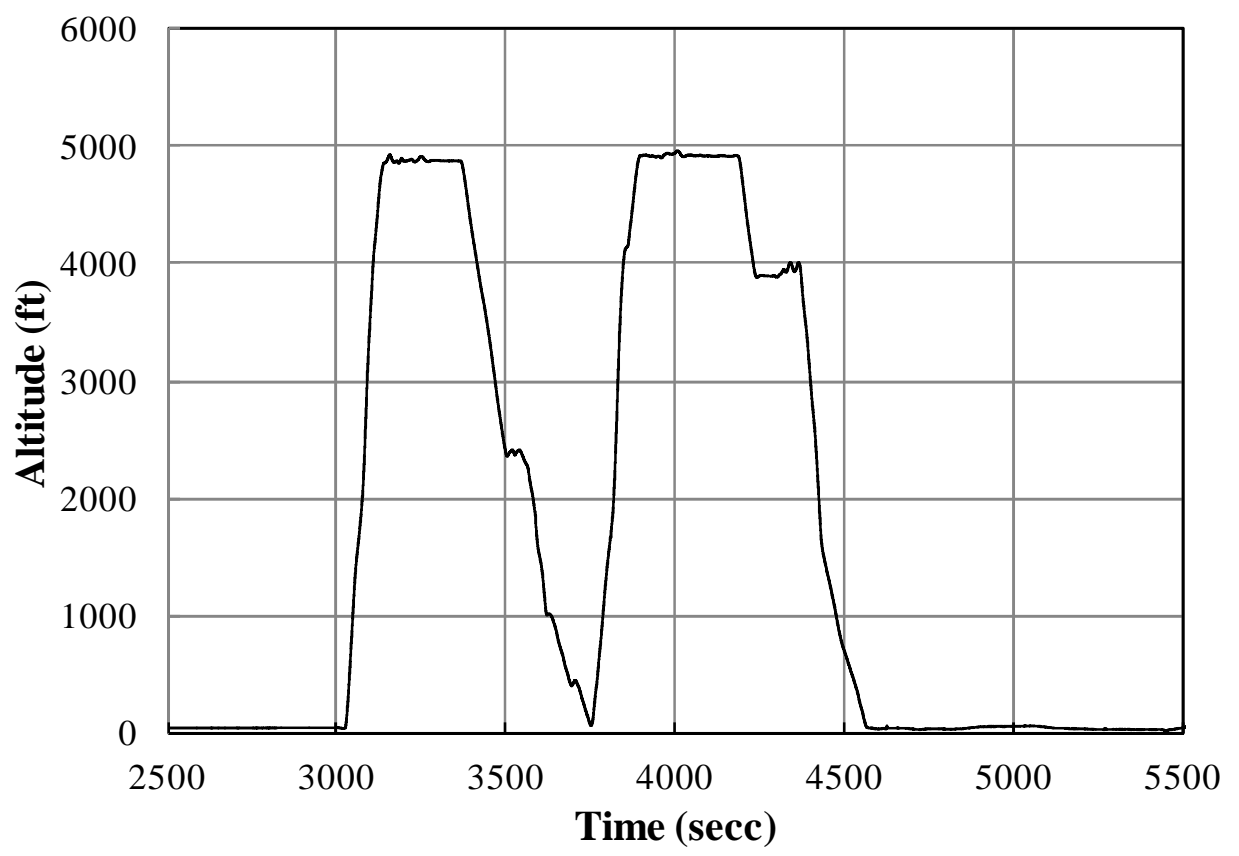

Figure 3. Altitude time history from two 5000 flights 
Table 5. Flight phase separation criteria

\begin{tabular}{|c|c|c|}
\hline Flight Phase & Start Time $\left(t_{1}\right)$ Identification & Stop Time $\left(t_{2}\right)$ Identification \\
\hline Taxi-Out & $\begin{array}{l}\text { Heading change }>20 \mathrm{deg}, \text { on } \\
\text { ground }\end{array}$ & $\left(\mathrm{t}_{1}\right.$ of Roll) minus $5 \mathrm{sec}$. \\
\hline Takeoff Roll & $n_{x}>0.15 \mathrm{~g}$, on ground & Pitch change $>3 \mathrm{deg}$. \\
\hline Rotation & $t_{2}$ of Roll & Pitch $>15$ deg or pitch change $>10$ deg \\
\hline Departure & $t_{2}$ of Rotation & Flaps retracted \\
\hline Climb & $\begin{array}{c}\mathrm{RC}>750 \text { fpm for } 20 \text { sec. and flaps } \\
\text { up }\end{array}$ & $\mathrm{RC}<750 \mathrm{fpm}$ for $20 \mathrm{sec}$. and flaps up \\
\hline Cruise & $\begin{array}{c}|\mathrm{RC}|<200 \text { fpm for } 20 \mathrm{sec} \text {. and flaps } \\
\text { up }\end{array}$ & $|\Delta \mathrm{h}|>250 \mathrm{ft}$ and flaps up \\
\hline Descent & $\begin{array}{c}\mathrm{RC}<-750 \mathrm{fpm} \text { for } 20 \text { sec. and flaps } \\
\text { up }\end{array}$ & Flaps are in transit or set to first detent \\
\hline Initial Approach & $\begin{array}{c}\text { Flaps in first detent and } \mathrm{RC} \leq 0 \text {, in } \\
\text { air }\end{array}$ & Flaps in second or third detent, in air \\
\hline Mid Approach & $\begin{array}{c}\text { Flaps in second detent and } \mathrm{RC} \leq 0, \\
\text { in air }\end{array}$ & Flaps in third detent, in air \\
\hline Final Approach & Flaps in third detent, in air & Touchdown minus 3 seconds \\
\hline Landing Roll & $\mathrm{t}_{2}$ of final approach & Heading change $>5 \mathrm{deg}$ \\
\hline $\begin{array}{l}\text { Runway Turn- } \\
\text { Off }\end{array}$ & $\mathrm{t}_{2}$ of landing roll & Heading change $<2$ deg for 5 sec. \\
\hline Taxi-In & $t_{2}$ of runway turn-off & Engine core $<11 \%$ minus 38 sec. \\
\hline
\end{tabular}

\section{RESULTS AND DISCUSSION}

\section{Available Data}

The results shown in the present article pertain to the data gathered from 242 flight files from the 5000 and 544 flight files from the XRS. The latter aircraft was never used for touch-and-goes, while the former was. Also, not all flight files contained flight information. Therefore, this data included 382 individual flights from the 5000 and 409 flight from the XRS. Suffice it to say that the data used for the present analysis covered 582 hours $(193,932 \mathrm{~nm})$ of operation from the 5000 and 1,137 hours $(492,162 \mathrm{~nm})$ from the XRS. These results are summarized in Table 6. It is evident that the 5000 was subjected to nearly the same number of Ground-Air-Ground (GAG) cycles as the XRS in almost half as much time because of the shorter average flight times. This can also be seen in Figure 4 where it is obvious that the almost half of the flights in the 5000 were under 30 minutes, while flight lasting up to three hours were not uncommon in the XRS.

\section{Flight Loads}

Flight overall maximum and minimum vertical load factors are presented in Figure 5, with some statistical information shown in Table 7. It is obvious that the 5000 was flown over a wider range of vertical load factors than was the XRS. Nonetheless, both aircraft were flown well within the range of design load factors of $+2.5 /-1.0 \mathrm{~g}$. 
Table 6. Number of flight files and flight data

\begin{tabular}{l|r|r}
\hline \multicolumn{1}{c|}{ Data } & $\begin{array}{c}\text { Global } \\
\mathbf{5 0 0 0}\end{array}$ & $\begin{array}{c}\text { Global } \\
\text { Express } \\
\text { XRS }\end{array}$ \\
\hline Total Number of Files & 242 & 544 \\
Number of Useful Files & 229 & 533 \\
Number of Flights & 382 & 409 \\
Total Flight Hours & 582 & 1,137 \\
Total Flight Distance (nm) & 193,932 & 492,162 \\
Average Flight Time (hr) & 1.52 & 2.78 \\
Average Flight Distance (nm) & 507.7 & $1,203.3$ \\
\hline
\end{tabular}

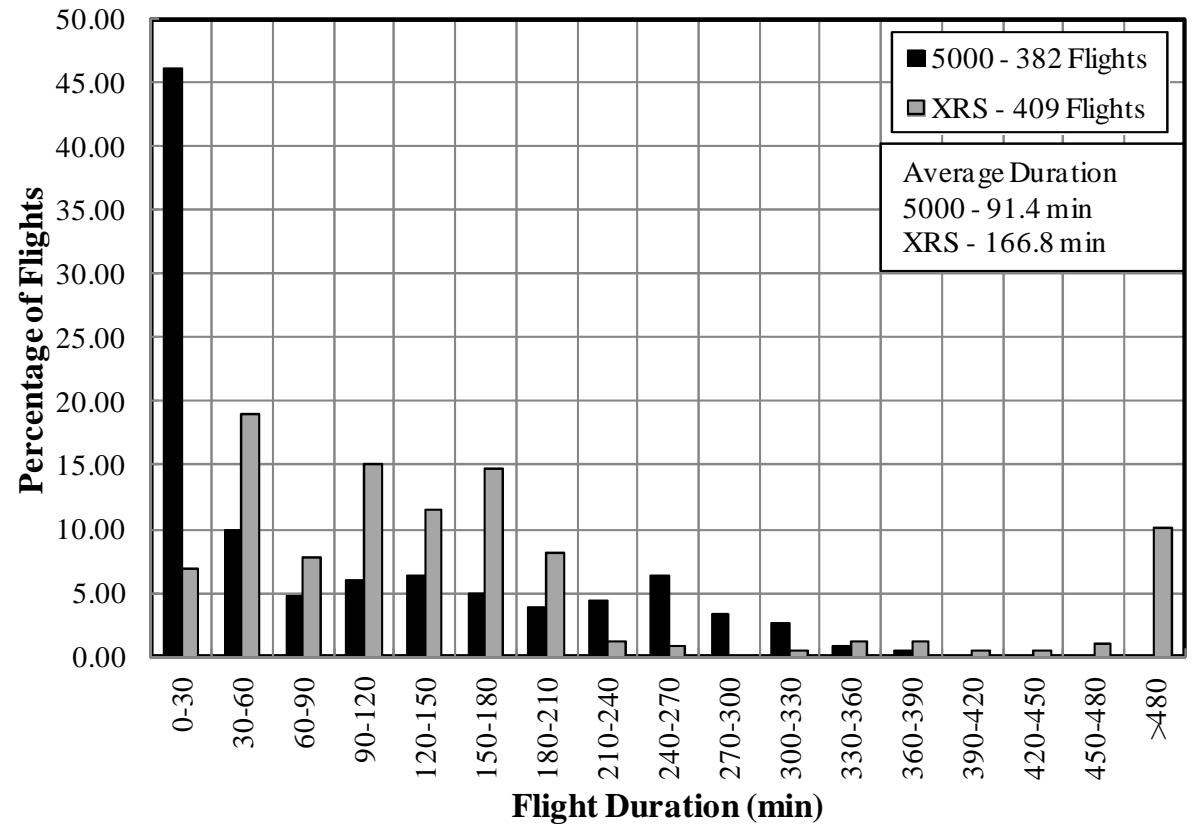

Figure 4. Distribution flights by duration

While a comprehensive study of the loads was performed, not enough flight time was available for every altitude band to result in statistically reliable information. This can be seen in Tables 8 and 9 where total times spent in each altitude band are presented for both airframes. Therefore, the following material will be limited to those cases where sufficient flight time was available. Even then, it is not possible to fit all the results within the confines of this article. Therefore only selective information will be presented and discussed here. Also, when examining each phase, the vertical loads were divided into those due to gusts and maneuvers using the two-second rule presented in Reference [13]. 


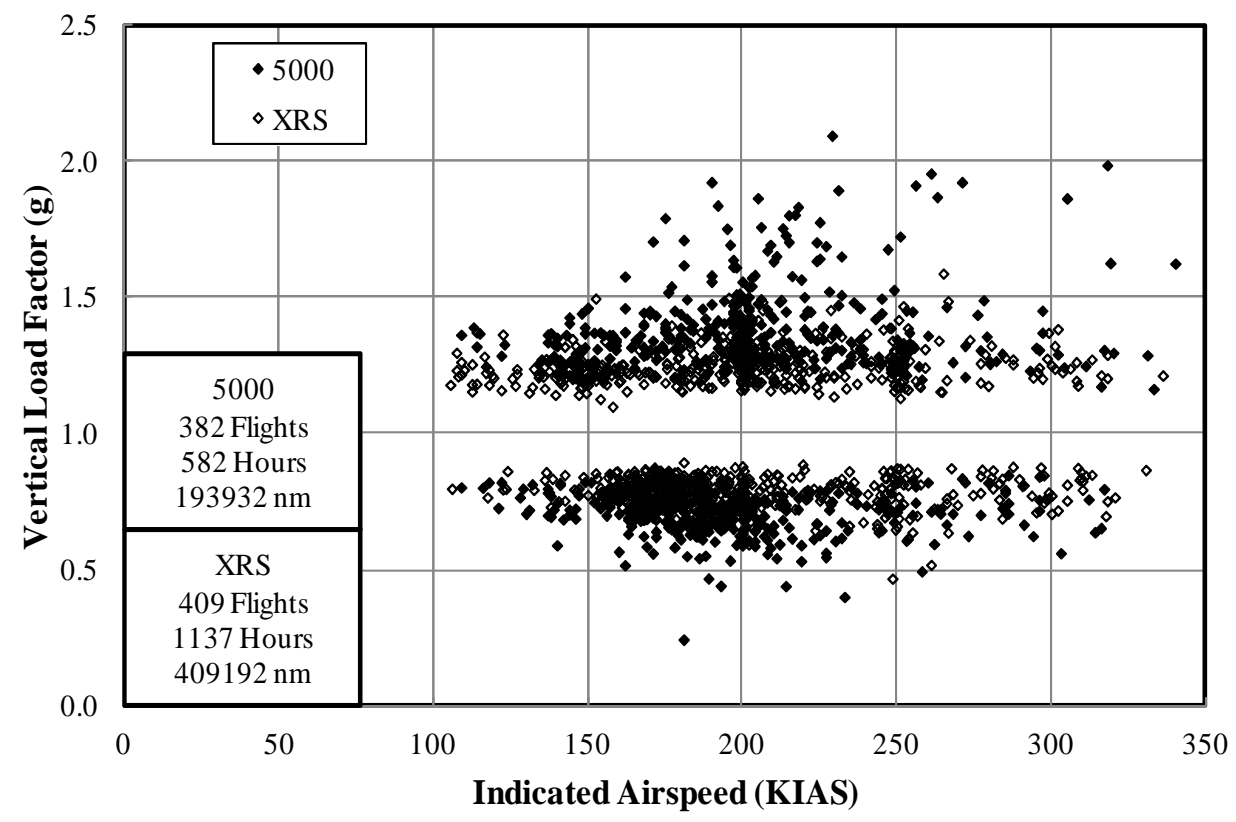

Figure 5. Overall max/min normal load factor

Table 7. Statistical data associated with Figure 5

\begin{tabular}{c|c|c}
\hline \multirow{2}{*}{ Vertical Load Factors (g) } & \multicolumn{2}{|c}{ Airframe } \\
\cline { 2 - 3 } & $\mathbf{5 0 0 0}$ & XRS \\
\hline \hline Maximum & 2.10 & 1.59 \\
Average & 1.39 & 1.25 \\
Standard Deviation & 0.16 & 0.07 \\
\hline Minimum & 0.25 & 0.47 \\
Average & 0.71 & 0.79 \\
Standard Deviation & 0.08 & 0.06 \\
\hline
\end{tabular}

Table 8. Cumulative hours spent in each altitude band by flight phase - Global 5000

\begin{tabular}{c|c|c|c|c|c|c|c}
\hline \hline $\begin{array}{c}\text { Alt. } \\
\text { Band } \\
\text { Ceiling } \\
\text { (ft) }\end{array}$ & Departure & Climb & Cruise & Descent & $\begin{array}{c}\text { Initial } \\
\text { Approach }\end{array}$ & $\begin{array}{c}\text { Middle } \\
\text { Approach }\end{array}$ & $\begin{array}{c}\text { Final } \\
\text { Approach }\end{array}$ \\
\hline \hline 500 & 1.10 & 0.00 & 0.97 & 0.01 & 15.33 & 0.62 & 0.01 \\
1500 & 1.02 & 0.25 & 1.85 & 0.05 & 2.66 & 2.57 & 0.05 \\
4500 & 2.89 & 3.73 & 49.93 & 3.88 & 19.83 & 11.09 & 3.88 \\
9500 & 2.66 & 4.72 & 69.80 & 7.29 & 12.83 & 10.86 & 7.29 \\
14500 & 0.00 & 4.93 & 37.07 & 6.48 & 11.49 & 2.04 & 6.48 \\
19500 & 0.00 & 4.56 & 27.99 & 5.43 & 1.81 & 4.18 & 5.43 \\
24500 & 0.00 & 6.71 & 6.70 & 7.28 & 0.33 & 0.15 & 7.28 \\
29500 & 0.00 & 7.31 & 29.88 & 6.81 & 0.45 & 0.25 & 6.81 \\
34500 & 0.00 & 7.30 & 31.00 & 6.01 & 1.28 & 0.95 & 6.01 \\
39500 & 0.00 & 3.40 & 54.26 & 2.48 & 2.52 & 0.09 & 2.48 \\
55000 & 0.00 & 0.54 & 100.83 & 0.51 & 0.00 & 0.31 & 0.51 \\
\hline
\end{tabular}


Table 9. Cumulative hours spent in each altitude band by flight phase-Global Express XRS

\begin{tabular}{c|c|c|c|c|c|c|c}
\hline \hline $\begin{array}{c}\text { Alt. } \\
\text { Band } \\
\text { Ceiling } \\
\text { (ft) }\end{array}$ & Departure & Climb & Cruise & Descent & $\begin{array}{c}\text { Initial } \\
\text { Approach }\end{array}$ & $\begin{array}{c}\text { Middle } \\
\text { Approach }\end{array}$ & $\begin{array}{c}\text { Final } \\
\text { Approach }\end{array}$ \\
\hline 500 & 1.75 & 0.00 & 0.00 & 0.00 & 0.00 & 0.00 & 5.88 \\
1500 & 1.87 & 0.01 & 0.02 & 0.01 & 0.79 & 2.09 & 8.54 \\
4500 & 0.29 & 5.24 & 8.17 & 7.21 & 6.72 & 4.41 & 1.56 \\
9500 & 0.00 & 11.07 & 8.76 & 18.98 & 0.87 & 0.18 & 0.14 \\
14500 & 0.00 & 13.04 & 8.72 & 17.52 & 0.00 & 0.00 & 0.00 \\
19500 & 0.00 & 13.12 & 5.64 & 14.72 & 0.00 & 0.00 & 0.00 \\
24500 & 0.00 & 13.25 & 11.48 & 13.83 & 0.00 & 0.00 & 0.00 \\
29500 & 0.00 & 14.05 & 6.16 & 12.81 & 0.00 & 0.00 & 0.00 \\
34500 & 0.00 & 15.88 & 7.48 & 12.56 & 0.00 & 0.00 & 0.00 \\
39500 & 0.00 & 16.06 & 55.63 & 13.82 & 0.00 & 0.00 & 0.00 \\
55000 & 0.00 & 8.96 & 733.05 & 8.72 & 0.00 & 0.00 & 0.00 \\
\hline
\end{tabular}

Cumulative occurrences of incremental normal acceleration during the climb phase are shown in Figure 6. Different parts of this figure offer a means of comparison between the two operations. Scarcity of data resulted in some scatter in these figures. Nonetheless, it is obvious from this figure that; 1) both aircraft were subjected to the same levels and frequencies of vertical gust loads, 2) gust loads occurred with increased frequency and magnitude at lower altitudes, and 3) the 5000 was flown over a wider range of maneuver load factors, consistent with the above discussion.

The same trends can also be seen in Figure 7, where the cumulative occurrences of gust and maneuver load factors are shown for the cruise phase. However, in this case, two additional trends can be seen very clearly. The first is that the XRS, being flown essentially as a transport aircraft, was not subjected to much maneuvering during cruise. Consequently, the volume of maneuver loads from this aircraft was extremely limited, despite the fact that it spent almost twice as long as the 5000 in cruise. Subsequently, the cumulative occurrences of the maneuver loads from the XRS showed significant scatter, making it impossible to arrive at any definitive conclusions regarding this aircraft.

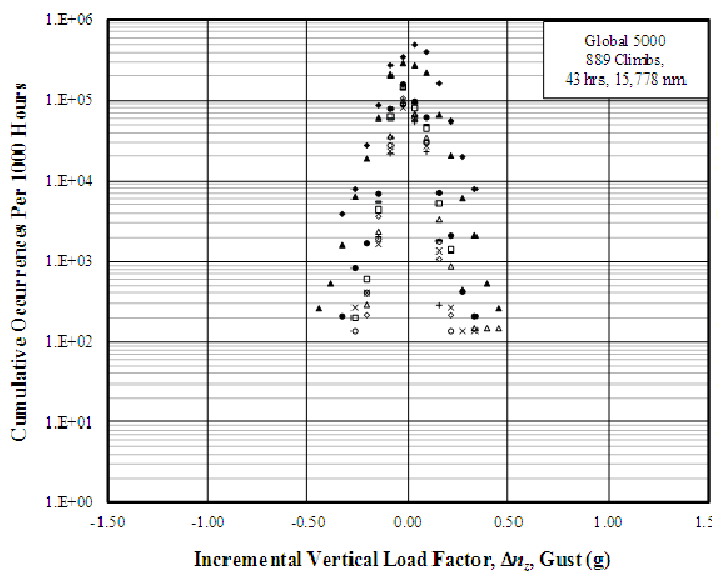

(a) Gust Loads - 5000

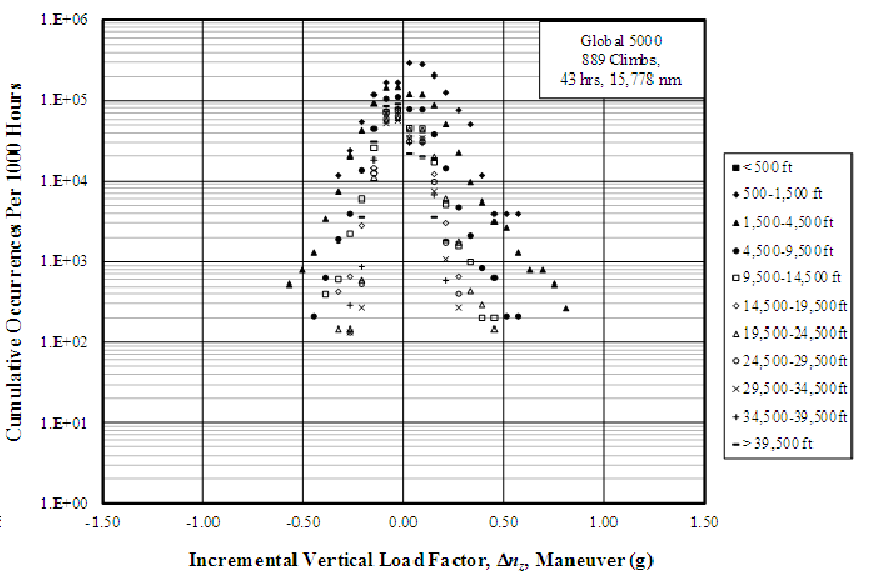

(b) Maneuver Loads - 5000

Figure 6. Cumulative occurrences of gust and maneuver incremental vertical load factor - Climb phase (continued) 


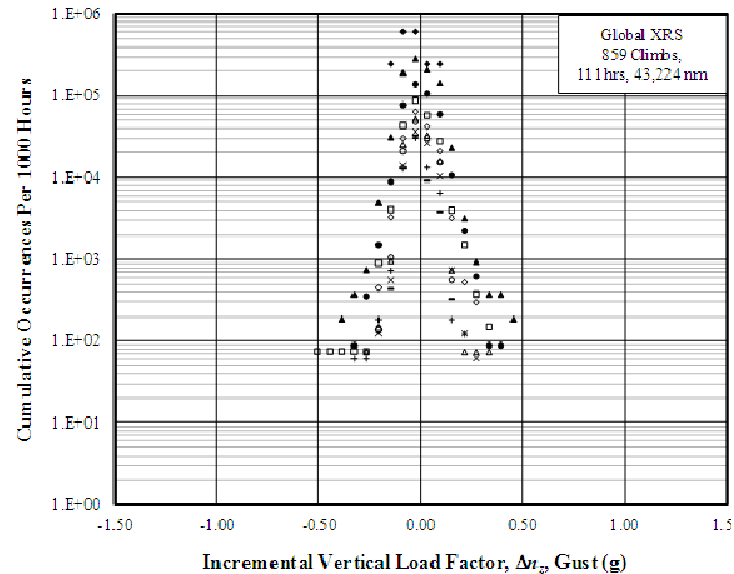

(c) Gust Loads - XRS

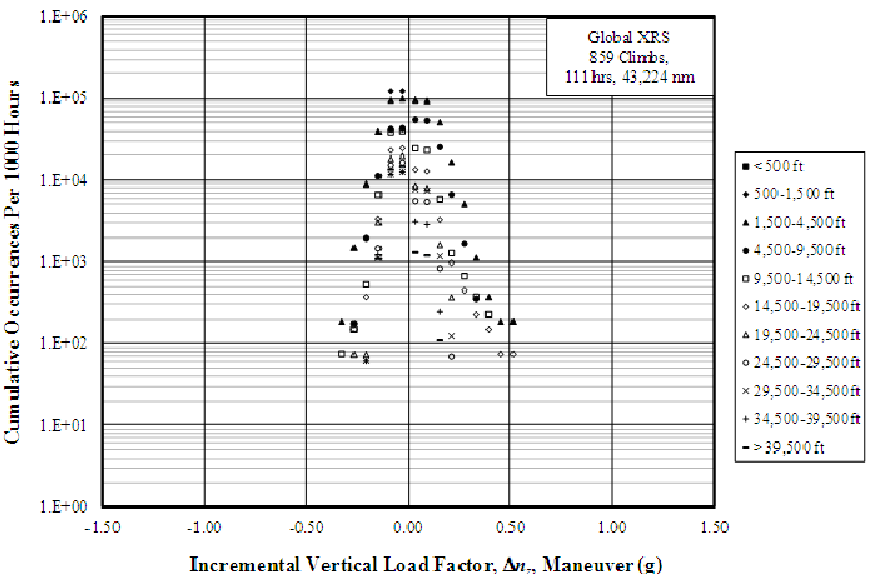

(d) Maneuver Loads - XRS

Figure 6. Cumulative occurrences of gust and maneuver incremental vertical load factor - Climb phase (concluded)

Secondly, Figure 7(b) shows the prevalence of positive maneuver loads, which is intuitively obvious. What is not clear is the cause of the dependence of the maneuver load on altitude. One would expect the magnitude and the frequency of occurrence of the maneuver loads to be independent of altitude. Similar trends in cumulative occurrences of incremental vertical gust and maneuver load factors for descent were also observed, as shown in Figure 8.

Finally, cumulative occurrences of incremental vertical load factor, combined for gust and maneuver and for all altitudes, are compared with two other aircraft in Figure 9. References [6] and [14] contain this information from Bombardier CRJ 100 (463 hours) and Embraer-145XR (88,035 hours), respectively. Despite the large difference between the total numbers of hours, the data from these two aircraft agreed quite well. Results presented here from the 5000 and the XRS pertain only to the combined climb, cruise, and descent phases.

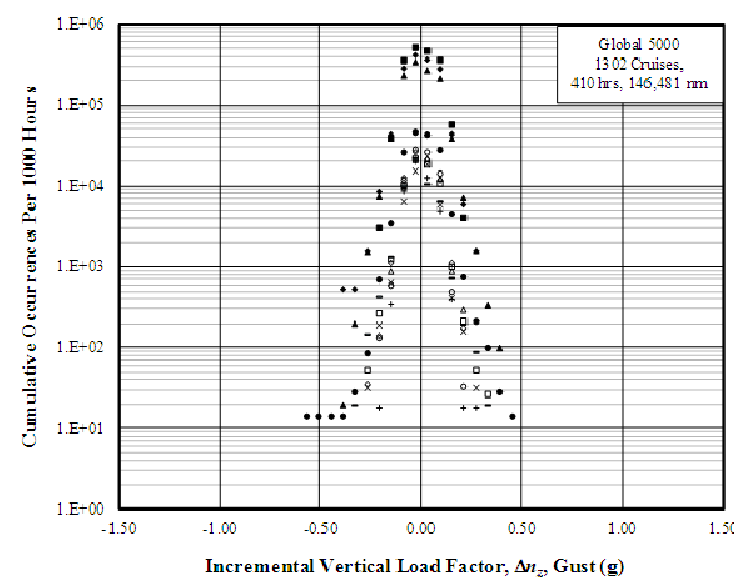

(a) Gust Loads - 5000

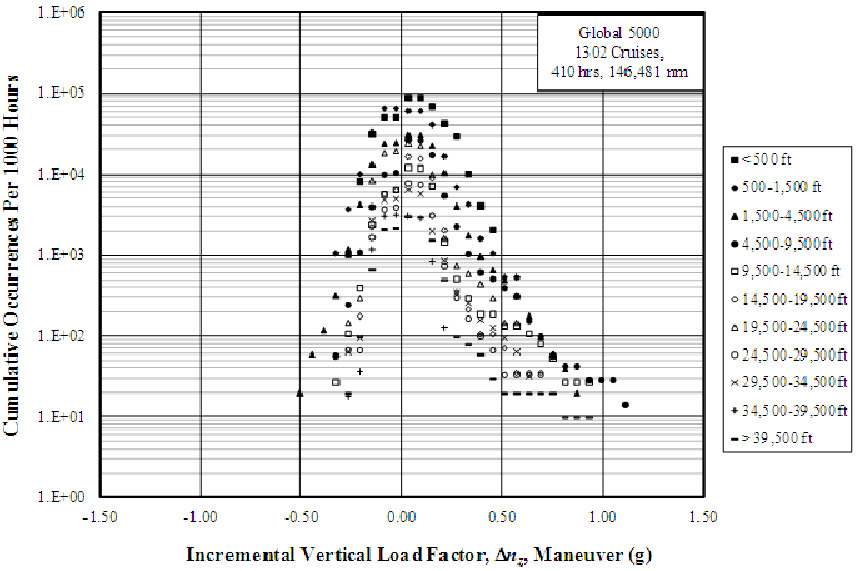

(b) Maneuver Loads - 5000

Figure 7. Cumulative occurrences of gust and maneuver incremental vertical load factor - Cruise phase (continued) 


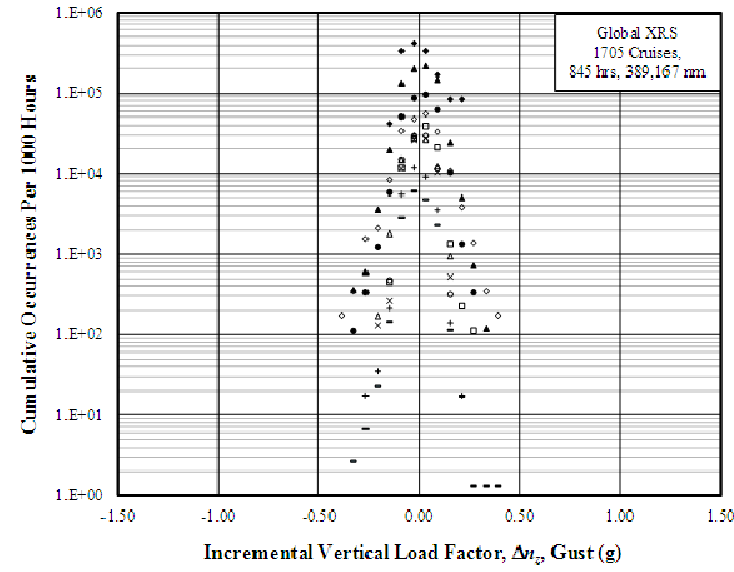

(c) Gust Loads - XRS

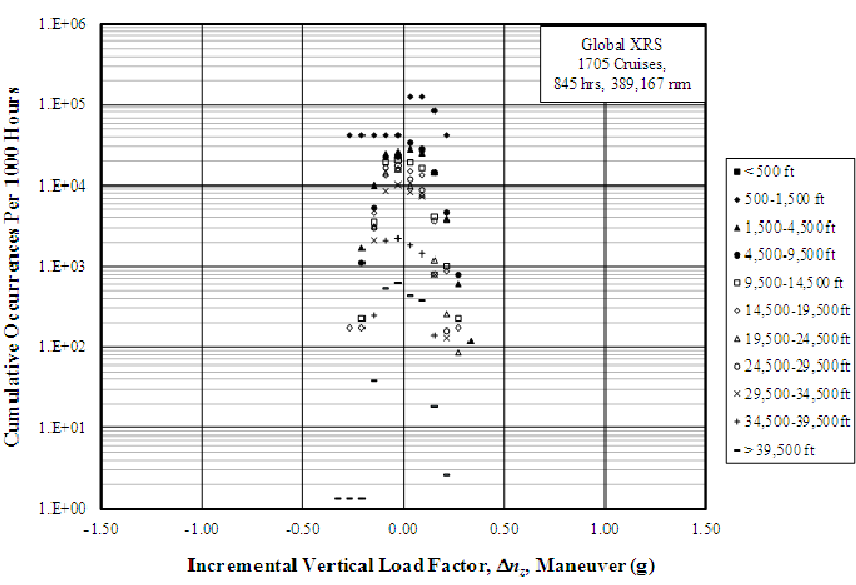

(d) Maneuver Loads - XRS

Figure 7. Cumulative occurrences of gust and maneuver incremental vertical load factor - Cruise phase (concluded)

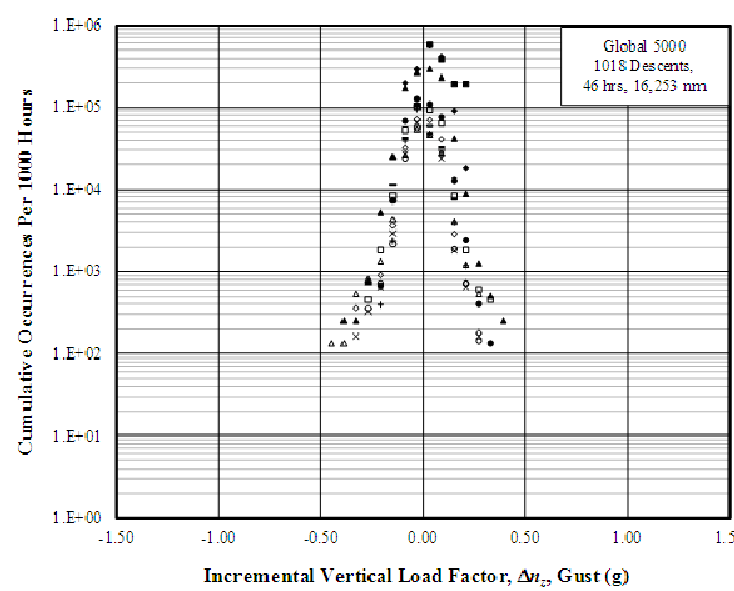

(a) Gust Loads - 5000

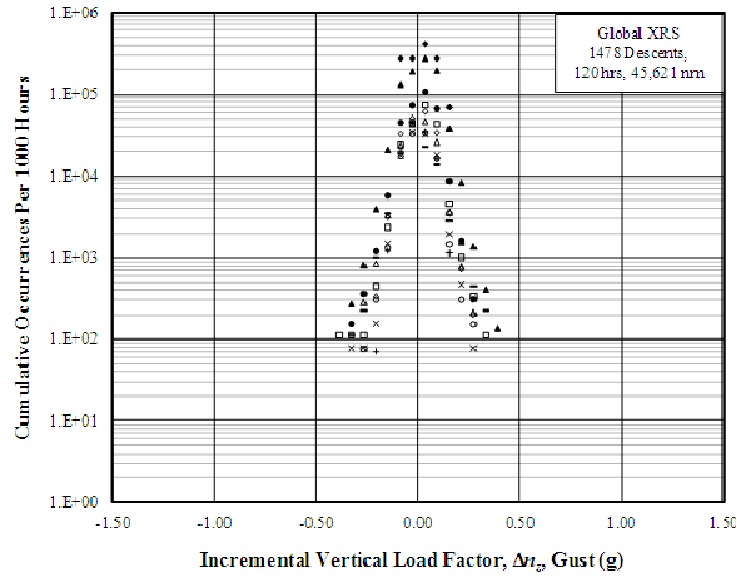

(c) Gust Loads - XRS

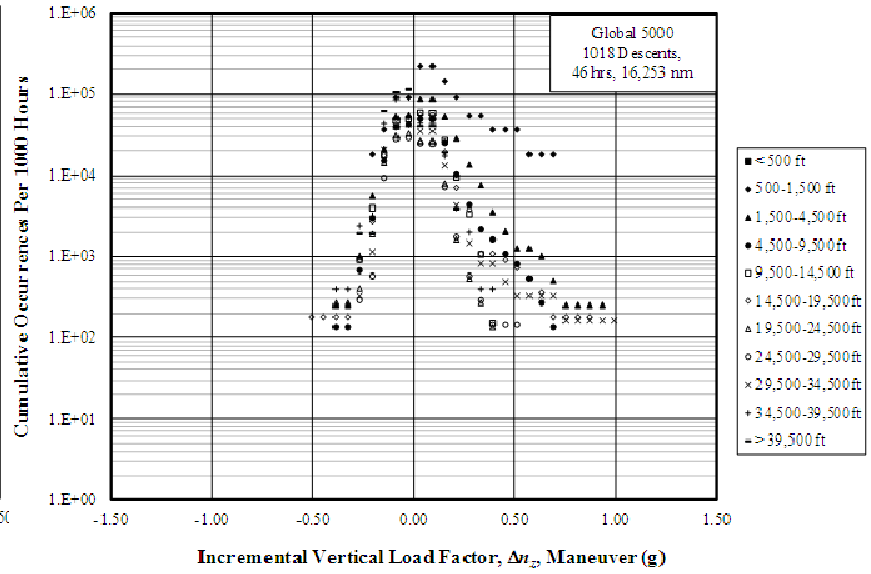

(b) Maneuver Loads - 5000

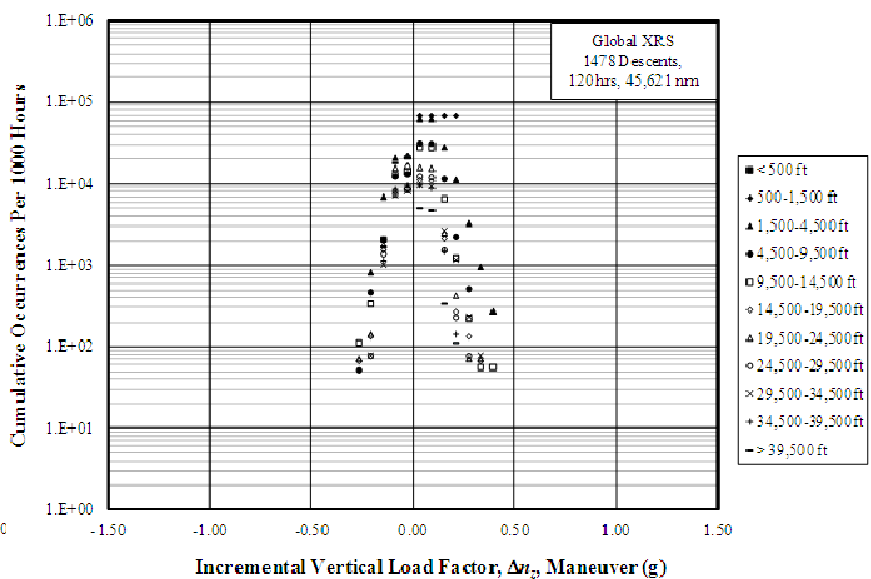

(d) Maneuver Loads - XRS

Figure 8. Cumulative occurrences of gust and maneuver incremental vertical load factor - Descent phase 


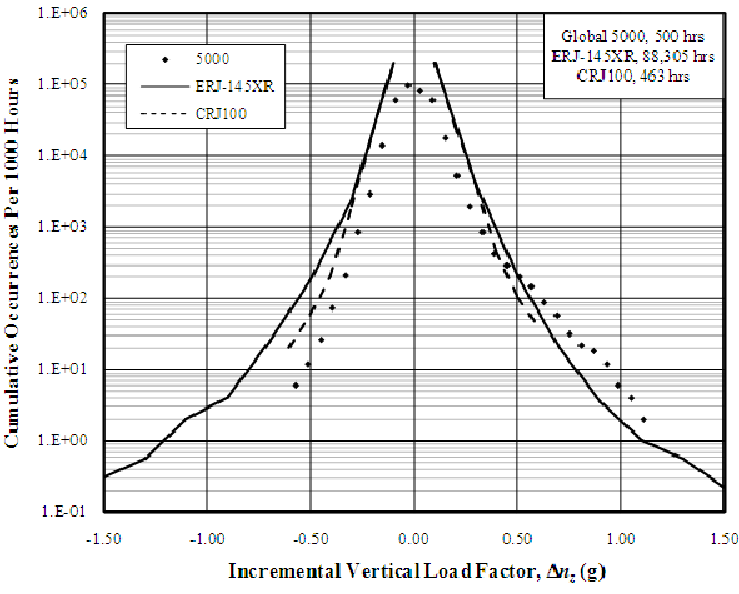

(a) Combined Loads - 5000

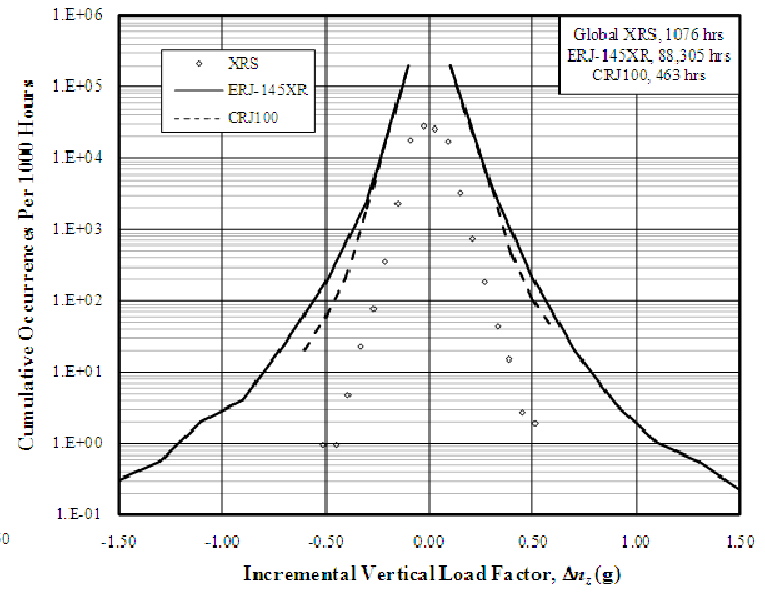

(b) Combined Loads - XRS

Figure 9. Comparison of the results with CRJ100 and ERJ-145XR - Climb, cruise, descent, all altitudes

Cumulative occurrences of the incremental vertical load factors from the 5000 compared quite favorably with those from both other aircraft. However, since the maneuver load factors were biased towards positive loads (Figure 7(b)), the combined loads were slightly larger than those of the ERJ and CRJ. However, the results obtained from the XRS fell far short of the other two aircraft both in magnitudes and in frequency of occurrence.

\section{Derived Gust Velocities}

Derived gust velocities were estimated from the normal accelerations, following methods outlined in a number of references (e.g. Reference [8]). Lift-curve slopes were estimated using the methods of Reference [11]. In the absence of detailed weights, typical basic operating weights shown in Table 1 were used. While this was smaller than the gross takeoff weight, it was an excellent estimate for these two aircraft because they were never flown with maximum number of passengers on board. Methods of References [15] and [16] were used to arrive at generalized exceedance curves. As it was shown in the previous section, dividing the data by flight phase and altitude band resulted in scarcity of information in some cases. Therefore, results were combined for cases where the aircraft was clean (i.e. no flap, slat, or landing gear deployment). However, the information was still divided into various altitude bands.

Cumulative occurrences of derived gust velocities are shown in Figure 10. Here, the results from the two airframes are shown separately to highlight any differences between the two. Again, the same scarcity of gust loads resulted in considerable scatter in the case of derived gust velocities. However, the dependence of this parameter on altitude is somewhat obvious in this figure. This figure also shows that there was more data available from the 5000 at lower altitudes due to the missions flown in this aircraft.

\section{SUMMARY AND CONCLUSIONS}

Operational flight loads were analyzed from two business jets, a Global 5000 and a Global Express XRS. The data consisted of actual flight data from 582 hours on the 5000 and 1,137 hours on the XRS. Due to the differing nature of the missions flown in the two aircraft, both were subjected to nearly the same number of ground-air-ground cycles. The overall flight $V$ - $n$ diagram did not show any cases where either aircraft approached its design limit load factors of $+2.5 /-1.0 \mathrm{~g}$. 


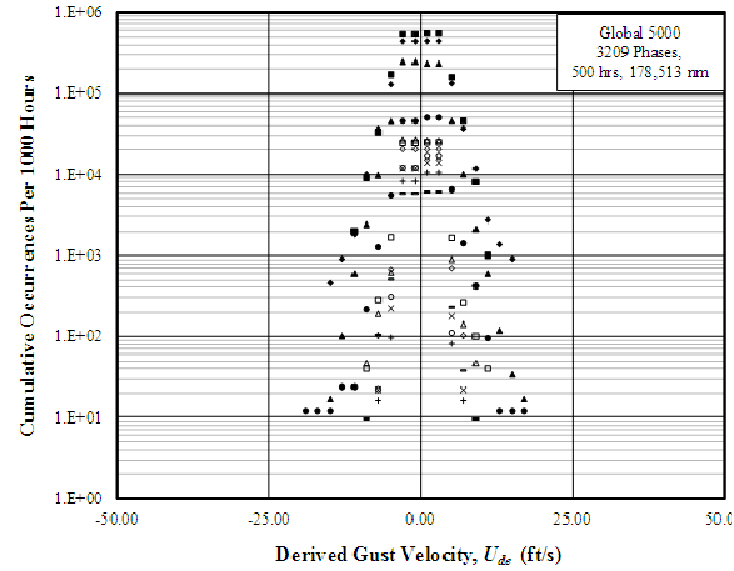

(a) 5000

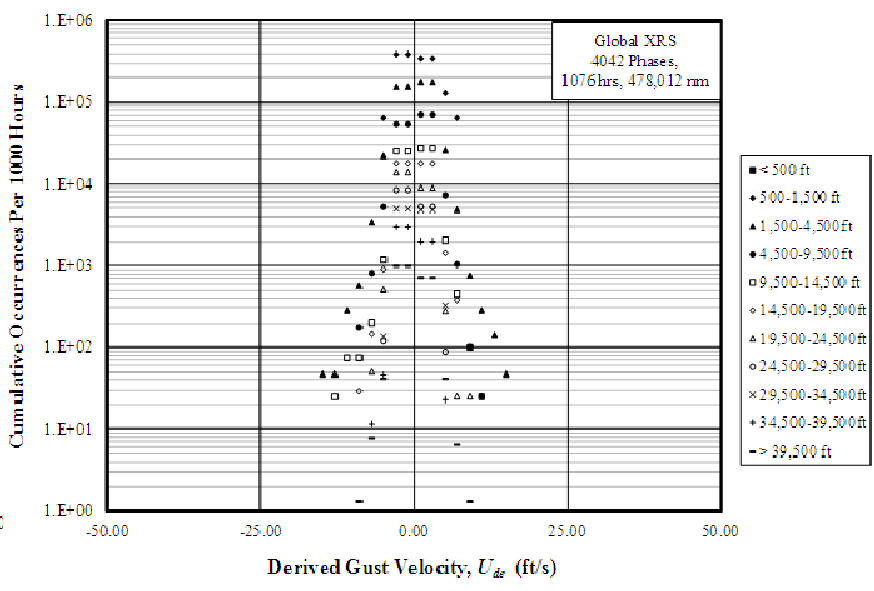

(b) $X R S$

Figure 10. Cumulative occurrences of derived gust velocities

- Combined climb, cruise, and descent

Flights were divided into various phases, and loads and turbulence data were categorized by altitude bands within each phase. This resulted in lack of sufficient data in some cases to arrive at statistically reliable conclusions.

Cumulative occurrences of incremental vertical gust load factors were shown to be comparable for the two airframes. However, maneuver load factors were spread over a wider range of values for the 5000 in every phase. Comparison of the combined gust and maneuver loads with those from a CRJ100 and an ERJ-145XR confirmed the same conclusion that the 5000, despite its lower number of flight hours, was subjected to a wider range of vertical load factors and at higher frequencies than the XRS. The same results were also shown by comparing the derived gust velocities, obtained from the vertical load factors.

The vertical load factors from the Global 5000 were approximately one order of magnitude more frequent than those of the Global Express XRS, stemming from the differences in their missions. This highlights the necessity of adjusting an airframe's maintenance and upkeep for the specific type of mission in which it is used.

The volume of flight data for this investigation was limited. Consequently, some scatter can be seen in the results presented above. Even though the present data allowed rational comparison of the two airframes, much more data is needed for definitive conclusions regarding cumulative occurrences of loads and gust velocities.

\section{ACKNOWLEDGMENTS}

The investigation presented here was supported by grant $08-\mathrm{G}-015$ from the Federal Aviation Administration. The authors would like to acknowledge the assistance of Mr. James Newcomb and Mr. James D'Ottavi, both retired from the FAA Tech Center, in obtaining and performing the preprocessing of the flight data. 


\section{REFERENCES}

1. Anonymous, "Aircraft Accident Report - Aloha Airlines, Flight 243, Boeing 737-200, N73711, Near Maui, Hawaii, April 28, 1988,” NTSB/AAR-89/03, June 14, 1989.

2. William M. Cavage, Tom DeFiore, and Terence Barnes. (1995). An Analysis of Ground-Flight Loads Measured on the Instrumented B-727 N40. Washington: U.S. Department of Transportation Federal Aviation Administration Office of Aviation Research and Development. (DOTIFMAR-95/82).

3. Skinn, D., Miedlar, P., Kelly, L. (1996). Flight Loads Data for a Boeing 737-400 in Commercial Operation," Federal Aviation Administration. Washington: U.S. Department of Transportation Federal Aviation Administration Office of Aviation Research and Development. (DOT/FAA/AR-95/21).

4. John Rustenburg, Donald A. Skinn, Daniel O. Tipps. (1998). Statistical Loads Data for Boeing 737-400 Aircraft in Commercial Operations. Washington: U.S. Department of Transportation Federal Aviation Administration Office of Aviation Research and Development. (DOT/FAA/AR-98/28).

5. John W. Rustenburg, Donald A. Skinn, and Daniel O. Tipps. (2002). Statistical Loads Data for the Airbus A-320 Aircraft in Commercial Operations. Washington: U.S. Department of Transportation Federal Aviation Administration Office of Aviation Research and Development. (DOT/FAA/AR-02/35).

6. John W. Rustenburg, Donald A. Skinn, and Daniel O. Tipps (2003). Statistical Loads Data for Bombardier CRJ100 Aircraft in Commercial Operations. Washington: U.S. Department of Transportation Federal Aviation Administration Office of Aviation Research and Development. (DOT/FAA/AR-03/44).

7. Todd Jones, John W. Rustenburg, Donald A. Skinn, Daniel O. Tipps, and Thomas DeFiore (2005). Statistical Data for the Boeing-747-400 Aircraft in Commercial Operations. Washington: U.S. Department of Transportation Federal Aviation Administration Office of Aviation Research and Development. (DOT/FAA/AR-04/44).

8. Daniel O. Tipps, Donald A. Skinn, John W. Rustenburg, Todd Jones, and David A. Harris. (2006). Statistical Loads Data for the Boeing 777-200ER Aircraft in Commercial Operations. Washington: U.S. Department of Transportation Federal Aviation Administration Office of Aviation Research and Development. (DOT/FAA/AR-06/11).

9. http://www.bombardier.com/en/aerospace/services-and-solutions/specialized-aircraftsolutions/specialized-platforms/bombardier-global-express-xrs-and-global-5000aircraft?docID $=0901260 \mathrm{~d} 8000 \mathrm{~cd} 52$

10. Model BD-700-1A10 (BD-700) Service Bulletin No. 700-31-026, April 30, 2007.

11. Etkin, B., and Reid, L. D. (1996). Dynamics of Flight: Stability and Control, $3^{\text {rd }}$ Ed., John Wiley \& Sons, Hoboken.

12. Alhambra L. Yee (2012). Operational Usage and Flight Loads Study of Global Express XRS Business Jet, M.S. Thesis in Aerospace Engineering, Wichita State University.

13. John Rustenburg, Donald A. Skinn, Daniel O. Tipps (1999). An Evaluation of Methods to Separate Maneuver and Gust Load Factors From Measured Acceleration Time Histories. Washington: U.S. Department of Transportation Federal Aviation Administration Office of Aviation Research and Development. (DOT/FAA/AR-99/14).

14. Todd Jones, John W. Rustenburg, Donald A. Skinn, Daniel O. Tipps, and Thomas DeFiore (2007). Statistical Loads Data for the Embraer-145XR Aircraft in Commercial Operations. Washington: U.S. Department of Transportation Federal Aviation Administration Office of Aviation Research and Development. (DOT/FAA/AR-07/61). 